http://jmscr.igmpublication.org/home/ ISSN (e)-2347-176x ISSN (p) 2455-0450 crossref DOI: https://dx.doi.org/10.18535/jmscr/v7i10.14

\title{
Minimal Erythema Dose to Narrow Band Ultraviolet - B in a Group of Libyan Patients
}

Authors

\section{Ali Mohamed Gargoom MD, Mustafa Nagmeddin Almukhtar MSc, Gamal Ahmed Duweb}

Dermatology Department, Faculty of Medicine, Benghazi University, Tripoli University,* Corresponding Author

Ali Mohamed Gargoom

Dermatology Department, Faculty of Medicine, Benghazi University, Benghazi Libya

\begin{abstract}
Background: Narrow-band ultraviolet $B(N B U V-B)$ is now widely considered as the first choice phototherapy modality for most photo-responsive skin conditions. In most dermatology centers where phototherapy is performed, the starting dose of NBUV-B phototherapy is calculated as a proportion of the minimal erythema dose (MED). This is in order to maximize the therapeutic response, decreasing therapeutic duration and reducing the risk of burning. Treatment with NBUV-B phototherapy is usually given three times per week, with a typical course requiring 18-30 treatments for disease clearance. Such treatment regimens require accurate assessment of the MED prior to commencing treatment in order to avoid overdoses or underdoes of NBUV-B.

Aim: The purpose of this study is to determine the MED of $311 \mathrm{~nm} N B U V-B$ in a group of Libyan patients. Methods: 150 patients with a various skin diseases who attending the phototherapy unit at Beer UstaMelad hospital of dermatology and venereology, Tripoli - Libya during an 8 months period were recruited for this prospective study. The studied skin diseases include psoriasis, vitiligo, atopic dermatitis and others. All patients were classified into skin types using the questionnaire of Fitzpatrick. Irradiation with $311 \mathrm{~nm} N B U V-B$ was performed over the right forearm by using a MED tester device (Dermalight ${ }^{\circledR}$ $80)$ then the results of the test were recorded 24 hours later.
\end{abstract}

Results: Among the studied patients; 82(54.7\%) patients were females and 68(45.3\%) patients were males. Their age ranged between 10 - 60 years while 30\% of the included group were in the age group of 31- 40 years. The patients were diagnosed on clinical grounds to have the following conditions; vitiligo $65(43.3 \%)$ patients, psoriasis 61(40.7\%) patients, eczema $8(5.3 \%)$ patients, pruritus $6(4 \%)$ patients and alopecia areata and lichen planus 5(3.3\%) patients each. According to Fitzpatrick's classification, the skin phototypes of the included series were; 15(10\%) patients of skin type III, $118(78.7 \%)$ patients of skin type IV and 17(11.3\%) patients of skin type $V$. The minimal required dose to produce an erythema for NBUV-B among the recruited patients was ranged between $300 \mathrm{~mJ} / \mathrm{cm} 2$ to $750 \mathrm{~mJ} / \mathrm{cm} 2$ with a mean dose of $484.7 \pm 82.2 \mathrm{~mJ} / \mathrm{cm} 2$.

Conclusions: The mean MED to $311 \mathrm{~nm} N B U V-B$ in Libyan patients was around $500 \mathrm{~mJ} / \mathrm{cm} 2$, and this can be used to decide the initial dose and treatment regimen of phototherapy for different skin diseases.

Phototherapy, Narrowband, Erythema, Minimal, Dose. 


\section{Introduction}

Narrow band ultraviolet-B (NB-UVB) phototherapy was originally introduced for the treatment of psoriasis but the list of indication for this convenient and effective modality of treatment is increasing ${ }^{(1)}$. Determining the starting appropriate irradiation dose of NB-UVB phototherapy which is known as the minimal erythema dose (MED) is a fundamental step in phototherapy practice. MED determination helps in administering the initial proper dose thereby avoiding the risk of under- or over- dosage at the start of the phototherapy course ${ }^{(2)}$. This will enhance the therapeutic efficacy andreduces the number of exposures required to clear the skin lesions ${ }^{(3)}$. Moreover, to avoid a higher cumulative dose of UVB. Usually the skin phototypeis used to determine the MED. This is not satisfactory as skin phototype is a poor predictor of MED. Furthermore, there are many variation in MED within the same skin phototype itself ${ }^{(4)}$. There are many methods used to determine the MED including; Ultraviolet-opaque template with TL01 panel, Filtered xenon arc lamp with liquid light guide, Waldman skin testing unit, Diffey template, Dermalight ${ }^{\circledR} 80$ MED-Testerand many others. The aim of this study is to determine the MED in a group of Libyan patients by using the Dermalight ${ }^{\circ} 80$ MED tester.

\section{Patients and Method \\ Patients}

A total of 150 male and female Libyan patients with various skin diseases attending phototherapy unit of (Beer UstaMelad) Hospital of Dermatology, Tripoli-Libya were included in this study.

\section{The inclusion Criteria Include}

1. Patients aged between 10 and 60 years.

2. Patients known to have a skin diseases responsive to phototherapy

\section{The exclusion Criteria Include}

1. Pregnant and lactating female.

2. History of photosensitivity.

3. Skin changes suggesting malignant transformation.

4. Collagen vascular disease.
5. Patients who received any form of phototherapy within the preceding 3 months.

6. Extremes of age ( $<10$ years or $>60$ years $)$.

\section{Method}

All informations regarding the nature of the testing procedure were explained to every patient and a verbal consent was obtained from each patient .Detailed history including; personal history, family history, photosensitivity history and past history of phototherapy were taking from every patient. Complete dermatological examination including; site, shape, number, and distribution of skin lesions were carried. The skin phototype for every patients enrolled in the present study was assessed by using "Fitzpatrick self-reported questionnaire",(5).

The Fitzpatrick scale is widely accepted test to assess the patient's skin phototype and designed to determining the skin color according to three main factors; genetic disposition, reaction to sun exposure and tanning habits. The response to each question is measured on a scale of zero to four. The response for all the questions is added to get the final score corresponding to the Fitzpatrick skin type.

The MED determination was carried out by the Dermalight ${ }^{\circledR} 80$ MED tester. The Dermalight $₫ 80$ MED tester with the emission field downwards were held on the inner aspect of the right forearm mid way between the wrist and the anticubital fossa (Figure 1).

After switching on the tester and kept steadily on the chosen place until the end of irradiation when the lamps switched off automatically. After that patient was instructed to protect the tested site from exposure to any natural or artificial light. 24hours later, the patient came back to the hospital for the reading of the tested site (Figure 2). A positive reading is considered as identifiable erythema with the margins of the phototesting part.Finally the corresponding MED value was taken from the table accompanied with the Dermalight@80 MED tester (Table 1).

\section{Statistical Analysis}

The results of the current study were analyzed using the Statistical Package for Social Science 
(SPSS) program software version 16. Correlations between variables were analyzed using Spearman's rank correlation coefficient (r) and one-way ANOVA post-hoc test (F). A p-value $<0.05$ was considered to be statistically significant.

\section{Results}

Among the enrolled 150 patients, 82 patients were females and 68 patients were males with male to female ratio (1:1.2) and their ages ranged between 10 to 60 years with a mean age $33.5 \pm 13.1$ years. $30 \%$ of the included series aged between 31 40 years, and the lowest percentage was $12 \%$ for the age group 51-60 years. Thirty one patients (20.7\%) had a history of previous phototherapy treatment, while the other 119 patients $(79.3 \%)$ are recently planned for phototherapy treatment.

Figure 3 illustrate the results of skin phototypes recorded according to Fitzpatrick self-reported questionnaire. The different clinical skin diseases enrolled in the present study is demonstrated in Table 2.

\section{MED and it's relation to patient characteristics}

The minimal dose required to produce an erythema for NB UV-B in the included patients in the present study was ranging from 300 to 750 $\mathrm{mJ} / \mathrm{cm}^{2}$ with a mean dose of $484.7 \pm 82.2 \mathrm{~mJ} / \mathrm{cm}^{2}$. The estimated MED was $440 \mathrm{~mJ} / \mathrm{cm}^{2}$ in 99 patients $(66 \%)$, and $580 \mathrm{~mJ} / \mathrm{cm}^{2}$ in 43 patients (28.7\%), $300 \mathrm{~mJ} / \mathrm{cm}^{2}$ in four patients $(2.7 \%)$, and $750 \mathrm{~mJ} / \mathrm{cm}^{2}$ in four patients $(2.7 \%)$.

When we studied the relation between the age and MED by using a Spearman correlation coefficient test we found that the relation is weak positive $(\mathrm{r}$ $=+0.241, \mathrm{P}$ value 0.003 ) (Table 3 ). When we studied the relation between gender and MED in male and female patients by using a Student's $t$ test the relation was statistically significant (P value 0.001) (Table 4). The relation between patients with a history of previous phototherapy treatment and the newly patients who are planned for phototherapy treatment and MED was statistically not significant a ( $\mathrm{P}$ value 0.138 ). (Table 5)

A statistically significant correlation was detected between MED and different skin phototypes when we used an ANOVA test and P value was (0.001) (Table 6).
The mean estimated MED of patients with different skin diseases included in this study were: for psoriasis patients the lowest MED was $300 \mathrm{~mJ} / \mathrm{cm}^{2}$ and the highest dose was $750 \mathrm{~mJ} / \mathrm{cm}^{2}$ with a mean dose $492 \mathrm{~mJ} / \mathrm{cm}^{2}$ (Figure 4), for eczema patients the lowest MED was $440 \mathrm{~mJ} / \mathrm{cm}^{2}$ and the highest dose was $580 \mathrm{~mJ} / \mathrm{cm}^{2}$ with a mean dose $475 \mathrm{~mJ} / \mathrm{cm}^{2}$ (Figure 5)

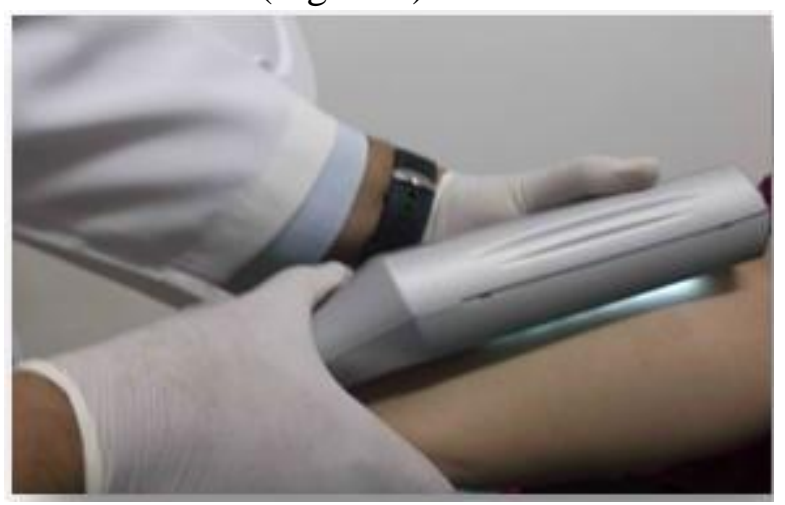

Figure (1): The Dermalight ${ }^{\circledR} 80$ MED tester held on the inner aspect of the forearm.

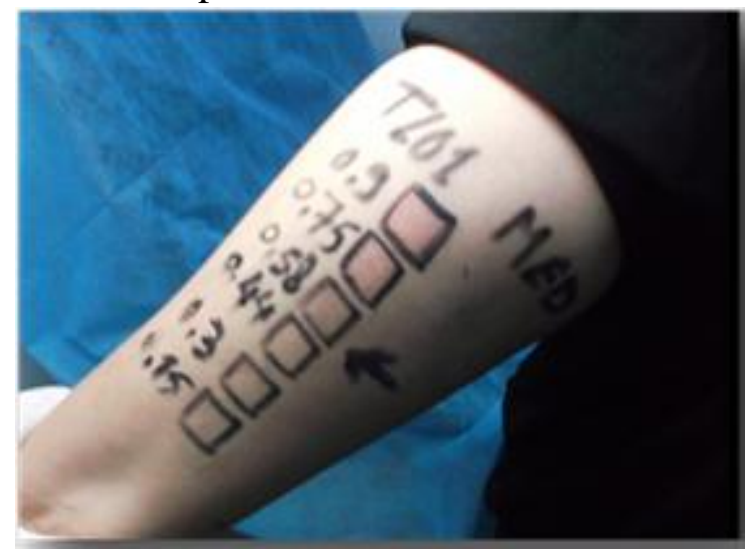

Figure (2): The tested site 24 hours later, the minimal erythema dose in this patient was assessed as $580 \mathrm{~mJ} / \mathrm{cm}^{2}$ according to accompanied table (Table1)

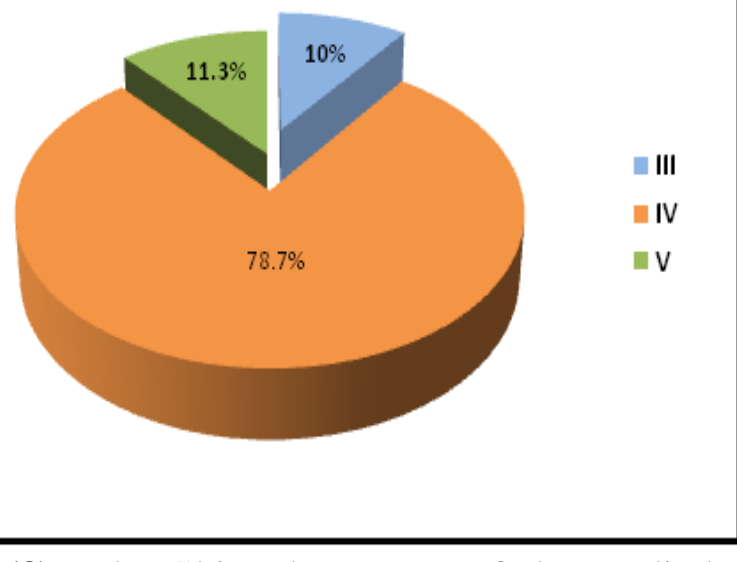

Figure (3): The Skin phototypes of the studied patients 


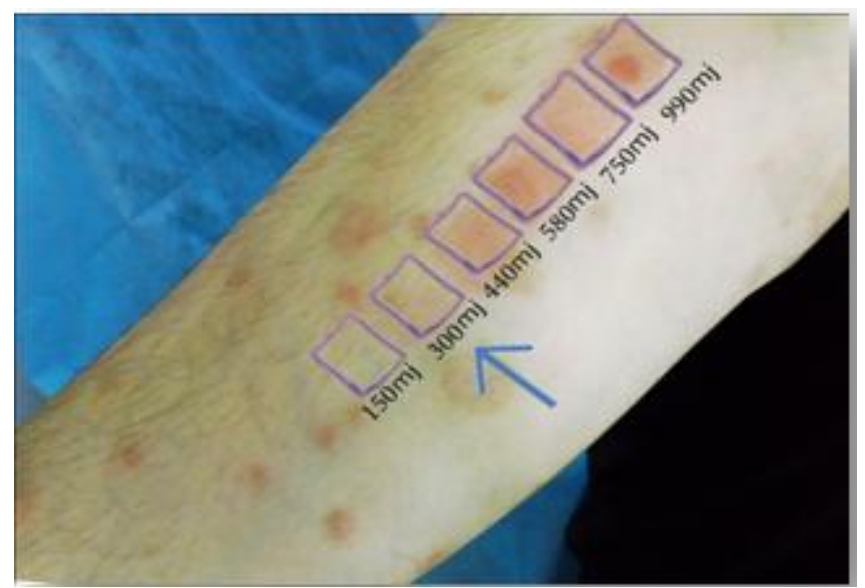

Figure (4): Psoriatic patient with MED to narrow band UVB at $300 \mathrm{~mJ} / \mathrm{cm}^{2}$.

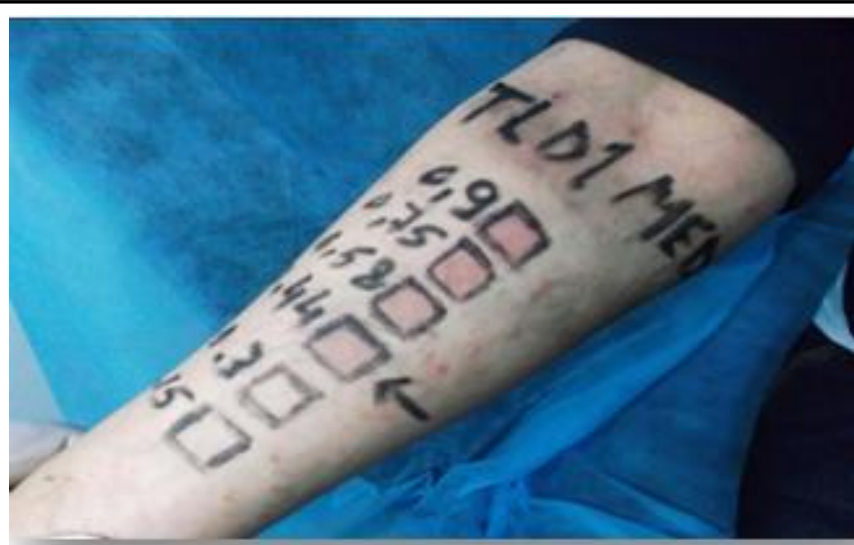

Figure (5): Eczema patient with MED of 440 $\mathrm{mJ} / \mathrm{cm}^{2}$.

Table (1): The corresponding dosage values of Dermalight $®$ MED- Tester

\begin{tabular}{|c|c|c|c|c|c|c|c|}
\hline & $\begin{array}{c}\text { Emission } \\
\text { rate }\end{array}$ & $\begin{array}{c}\text { Test field } \\
1 \\
100 \%\end{array}$ & $\begin{array}{c}\text { Test field } \\
2 \\
83 \%\end{array}$ & $\begin{array}{c}\text { Test field } \\
3 \\
65 \%\end{array}$ & $\begin{array}{c}\text { Test field } \\
4 \\
49 \%\end{array}$ & $\begin{array}{c}\text { Test field } \\
5 \\
34 \%\end{array}$ & $\begin{array}{c}\text { Test field } \\
6 \\
17 \%\end{array}$ \\
\hline Skin type & $\begin{array}{c}\text { Time } \\
\text { Min: Sec }\end{array}$ & $\begin{array}{l}\text { Dose } \\
\left(\mathrm{J} / \mathrm{cm}^{2}\right)\end{array}$ & $\begin{array}{l}\text { Dose } \\
\left(\mathrm{J} / \mathrm{cm}^{2}\right)\end{array}$ & $\begin{array}{l}\text { Dose } \\
\left(\mathrm{J} / \mathrm{cm}^{2}\right)\end{array}$ & $\begin{array}{l}\text { Dose } \\
\left(\mathrm{J} / \mathrm{cm}^{2}\right)\end{array}$ & $\begin{array}{l}\text { Dose } \\
\left(\mathrm{J} / \mathrm{cm}^{2}\right)\end{array}$ & $\begin{array}{l}\text { Dose } \\
\left(\mathrm{J} / \mathrm{cm}^{2}\right)\end{array}$ \\
\hline \multirow[t]{2}{*}{1} & $0: 36$ & 0,400 & 0,332 & 0,260 & 0,196 & 0,136 & 0,068 \\
\hline & $0: 41$ & 0,450 & 0,374 & 0,293 & 0,221 & 0,153 & 0,077 \\
\hline \multirow[t]{2}{*}{2} & $0: 45$ & 0,500 & 0,415 & 0,325 & 0,245 & 0,170 & 0,085 \\
\hline & $0: 55$ & 0,600 & 0,498 & 0,390 & 0,294 & 0,204 & 0,102 \\
\hline \multirow[t]{2}{*}{3} & 1:04 & 0,700 & 0,581 & 0,455 & 0,343 & 0,238 & 0,119 \\
\hline & $1: 13$ & 0,800 & 0,064 & 0,520 & 0,392 & 0,272 & 0,136 \\
\hline 4 & $1: 22$ & 0,900 & 0,747 & 0,585 & 0,441 & 0,306 & 0,153 \\
\hline
\end{tabular}

Table (2): The clinical diagnosis of the studied patients.

\begin{tabular}{|l|c|c|}
\hline $\begin{array}{l}\text { The clinical } \\
\text { diagnosis }\end{array}$ & Frequency & Percentage \\
\hline \hline Vitiligo & 65 & 43.3 \\
\hline Psoriasis & 61 & 40.7 \\
\hline Eczema & 8 & 5.3 \\
\hline Pruritus & 6 & 4 \\
\hline Lichen planus & 5 & 3.3 \\
\hline Alopecia areata & 5 & 3.3 \\
\hline \hline Total & 150 & 100 \\
\hline
\end{tabular}


Table (3): The Correlation between age and MED (Spearman rank correlation)

\begin{tabular}{|c|c|c|c|c|}
\hline & & & AGE & MED \\
\hline \multirow[t]{2}{*}{ Spearman's rho } & AGE & $\begin{array}{l}\text { Correlation Coefficient } \\
\text { Sig. (2-tailed) } \\
\mathrm{N} \\
\end{array}$ & $\begin{array}{c}1.000 \\
\cdot \\
150 \\
\end{array}$ & $\begin{array}{l}.241^{* *} \\
.003 \\
150 \\
\end{array}$ \\
\hline & MED & $\begin{array}{l}\text { Correlation Coefficient } \\
\text { Sig. (2-tailed) } \\
\mathrm{N}\end{array}$ & $\begin{array}{l}.241^{* * *} \\
.003 \\
150\end{array}$ & $\begin{array}{c}1.000 \\
. \\
150\end{array}$ \\
\hline
\end{tabular}

Correlation is significant at the 0.01 level (2-tailed).

Table (4): Gender and MED in male and female studied patients (Student's T test; for independent samples)

\begin{tabular}{|l|c|c|c|}
\hline Gender & Frequency & Mean \pm SD & P value \\
\hline \hline Male & 68 & $513.8 \pm 93.2$ & $\mathbf{0 . 0 0 1}$ \\
\hline Female & 82 & $460.5 \pm 62.7$ & \\
\hline
\end{tabular}

Table (5): Correlation between patients with previous phototherapy treatment and MED (Student's T test; for independent samples).

\begin{tabular}{|l|c|c|c|}
\hline H/O Previous phototherapy & Frequency & Mean \pm SD & $P$ value \\
\hline \hline Yes & 31 & $504.2 \pm 82.3$ & \multirow{2}{*}{$\mathbf{0 . 1 3 8}$} \\
\hline No & 119 & $479.6 \pm 81.7$ & \\
\hline
\end{tabular}

Table (6): The MED percentage in different skin phototypes

\begin{tabular}{|c|c|c|c|c|c|c|}
\hline & & & \multicolumn{3}{|c|}{ Skin Phototype } & \multirow[b]{2}{*}{ Total } \\
\hline & & & III & IV & $\mathbf{V}$ & \\
\hline \multirow[t]{8}{*}{ MED } & 300 & Count & 4 & 0 & 0 & 4 \\
\hline & & $\%$ within Skin Phototype & $26.7 \%$ & $0.0 \%$ & $0.0 \%$ & $2.7 \%$ \\
\hline & 440 & Count & 10 & 86 & 3 & 99 \\
\hline & & $\%$ within Skin Phototype & $66.7 \%$ & $72.9 \%$ & $17.6 \%$ & $66.0 \%$ \\
\hline & 580 & Count & 1 & 30 & 12 & 43 \\
\hline & & $\%$ within Skin Phototype & $6.7 \%$ & $25.4 \%$ & $70.6 \%$ & $28.7 \%$ \\
\hline & 750 & Count & 0 & 2 & 2 & 4 \\
\hline & & $\%$ within Skin Phototype & $.0 \%$ & $1.7 \%$ & $11.8 \%$ & $2.7 \%$ \\
\hline \multirow[t]{2}{*}{ Total } & & Count & 15 & 118 & 17 & 150 \\
\hline & & $\%$ within Skin Phototype & $100.0 \%$ & $100.0 \%$ & $100.0 \%$ & $100.0 \%$ \\
\hline
\end{tabular}

\section{Discussion}

MED determination is crucial for rational phototherapy treatment. MED readings are essential for the stating dose and subsequent increments of UV irradiation. Although this procedure may at first looks simple but it is complicated by a number of factors and the resulting MED value will depend on the subjective interpretation of the observer, the skin site tested, the patient's age, the ambient temperature, the degree of pigmentation of the patient's skin, and of course their skin phototype. Furthermore, individuals with the same skin phototype can have different MEDs. ${ }^{(4)}$ 
The age may play a role where Gilchrest et al mentioned that MED may be affected by extreme of age in which very young children and elderly tend to have a lower $\mathrm{MED}^{(6)}$. In contrast to this, Cox et al found that there is no differences in visually assessed MEDs in subjects $<25$ years of age and subjects aged $>60$ years. ${ }^{(7)}$

In this study our patients were ranged between 10 to 60 years and the extremes of age are not involved. According to the result of our study the correlation between age and MED within this range were weakly positive.

The men have a slightly higher prevalence of sunburn than women as Brown et al. reported in 2006. ${ }^{(8)}$ But our data has shown statistically significant difference between males and females regarding MED denoting a gender difference in the function of skin as regard photoprotection, as males have high MED in comparison with females It has been found that several factors such as eye color, hair color, skin type and skin color are major determinants of skin sensitivity. ${ }^{(9)}$

Clinicians either rely on skin type as a predictor of erythema response or use phototesting to obtain the MED in order to calculate the starting dose of NB-UVB.

Skin photo typing is a simple screening method used to predict skin reactions to ultraviolet radiation. The original concept of skin typing was proposed by Fitzpatrick in 1975 on the basis of reported susceptibilities to burning and tanning to UVR. However, this concept was based on reports on white skin. There are few reports on brown skin. At first, brown skin was grouped simply as skin type $\mathrm{V}$, in addition to the skin types I through IV of white skin by Pathak and Fitzpatrick. Later, brown skin was divided into three groups: type IV for light brown skin, type $\mathrm{V}$ for dark brown skin, and type VI for black skin.

There is a good evidence that assessment of the skin type in white patients is not a good predictor of erythema response as reported by Cox et $\mathrm{al}^{(10)}$. This observation has been supported by Gorden et $\mathrm{al}^{(11)}$. A study by Leslie et al was also unable to show a correlation between skin types and MED (12). In contrast, a study from Korea did find an association between skin type and MED in psoriatic patients ${ }^{(13)}$. In case of Chinese and Asian skin the skin types correlated fairly with the MED to UVA and $\mathrm{UVB}^{(14)}$. On Indian subjects Pai et al found that fair skin developed erythema much earlier and at lower dose than needed by individuals with type $\mathrm{V} \operatorname{skin}^{(3)}$. However, a significant increase in MED measurements from skin types I-III compared with skin types IV-VI as reported by Alora and Tylor ${ }^{(15)}$. Also in another study from Bahrain a significant correlation was noted between skin types and $\mathrm{MED}^{(16)}$. Our data although limited, pointed out a statistically significant correlation between skin types and MED, and no statistically significant correlation was detected between the clinical diagnosis and MED.

The established MEDs for the skin of Libyan patients in this study were $300-580 \mathrm{~mJ} / \mathrm{cm}^{2}$ with a mean $412 \mathrm{~mJ} / \mathrm{cm}^{2}$ for type III, $440-750 \mathrm{~mJ} / \mathrm{cm}^{2}$ with a mean $480.8 \mathrm{~mJ} / \mathrm{cm}^{2}$ for type IV, and also $440-750 \mathrm{~mJ} / \mathrm{cm}^{2}$ with a mean $575.3 \mathrm{~mJ} / \mathrm{cm}^{2}$ for type V. Our results show that there is a step wise increase in the average MED from skin types III to V. Although the skin types and MED were correlated, there is a wide range of MEDs within each skin type and a substantial degree of overlap in the MED range among different skin types. Our values of MED are differ than those reported from other studies and this could be due to variations in instrumentation, methods of measurement and the genetic differences of different populations. In one study from India, Tejasvi et al reported the average MED for narrowband UVB exposure for type IV to be ranged between $500-1100 \mathrm{~mJ} / \mathrm{cm}^{2}$ and type $\mathrm{V}$ skin to be ranged between 750-1100 $\mathrm{mJ} / \mathrm{cm}^{2}$, with a mean dose $1000 \mathrm{~mJ} / \mathrm{cm}^{2}{ }^{(4)}$. In a study from Taiwan, they found MEDs to be 275 $\mathrm{mJ} / \mathrm{cm}^{2}$ for skin type III and $312 \mathrm{~mJ} / \mathrm{cm}^{2}$ for skin type IV with a mean average dose $300 \mathrm{~mJ} / \mathrm{cm}^{2}{ }^{(17)}$. Thus, these studies variations strengthen the need for more accurate MED determination and individual patient testing rather than application of blanket guidelines.

\section{Conclusion}

The mean MED to $311 \mathrm{~nm}$ NBUV-B in Libyan patients was around $500 \mathrm{~mJ} / \mathrm{cm} 2$, and this can be used to decide the initial dose and treatment regimen of phototherapy for different skin diseases 


\section{References}

1. Sally H. Ibbotson. A Perspective on the Use of NB-UVB Phototherapy vs. PUVA Photochemotherapy. Front Med (Lausanne). 2018; 5: 184.

2. Heckman, C.J., Chandler, R., Kloss, J.D., Benson, A., Rooney, D., Munshi, T., Darlow, S.D., Perlis, C., Manne, S.L., Oslin, D.W. Minimal Erythema Dose (MED) Testing. J. Vis. Exp. (75), e50175, doi:10.3791/50175 (2013).

3. Pai GS, Vinod V, Krishna V. Med estimation for narrow band UV-B on type IV and type $\mathrm{V}$ skin in India. Indian $\mathrm{J}$ Dermatol Venereol Leprol. 2002; 68: 140141

4. TejasVvi T, Sharma VK, Kaur J. Determination of minmal erythema dose for narrow band UVB radiation in north Indian patients: Comparison of visual and derma spectrometer ${ }^{\circledR}$ readings. Indian J DermatolVenereolLeprol. 2007;73:97-99.

5. Sachdeva S. Fitzpatrick $s$ kin typing: Applications in dermatology. Indian $\mathbf{J}$ Dermatol Venereol Leprol 2009;75:93-6.

6. Gilchrest BA, Stoff JS and Soter NA (1982): Chronologic aging alters the response to ultraviolet-induced inflammation in human skin. $\mathbf{J}$ Invest Dermatol; 79(1):11-5.

7. Cox NH, Diffey BL, Farr PM.The relationship between chronological age and the erythemal response to ultraviolet B radiation. Br J Dermatol 1992; 126: 31519.

8. Brown TT, Quain RD, Troxel AB and Gelfand JM (2006): The epidemiology of sunburn in the US population in 2003. $\mathbf{J}$ Am Acad Dermatol; 55(4):577-83.

9. Lock-Andersen J, Drzewiecki KT and Wulf HC (1999): Eye and hair colour, skin type and constitutive skin pigmentation as risk factors for basal cell carcinoma and cutaneous malignant melanoma. A Danish case-control study. Acta Derm Venereol; 79(1):74-80.

10. Cox NH, Farr PM, Diffey BL. A comparison of the dose- response relationship for psoralen-UVA erythema and UVB erythema. Arch Dermatol 1989; 125: 1653-7.

11. Gordon PM, Saunders PJ, Diffey BL et al. Phototesting prior to narrowband (TL-01) ultraviolet B phototherapy. Br J Dermatol 1998; 139: 811-14.

12. Leslie KS, Lodge E, Garioch JJ. A comparison of narrowband (TL-01) UVBinduced erythemal response at different body sites. Clin Exp Dermatol 2005; 30:337-9.

13. Youn JI, Oh JK, Kim BK, Suh DH, Chung $\mathrm{JH}, \mathrm{Oh} \mathrm{SJ}$, et al. Relationship between skin photo type and MED in Korean brown skin. Photodermatol Photoimmunol Photomed1997;13:208-11.

14. Wee LK, Chong TK, Quee DK. Assessment of skin types, skin colours and cutaneous responses to ultraviolet radiation in an Asian population. Photodermatol Photoimmunol Photomed 1997;13:169-72.

15. Alora MB, Taylor CR. Narrow-band (311 nm) UVB phototherapy: an audit of the first years' experience at the Massachusetts General Hospital. Photodermatol Photoimmunol Photomed 1997; 13:82-4.

16. Venkataram M N, Haitham Al Amiri, Correlating skin phototype and minimum erythema dose in Arab skin. International Journal of Dermatology 2003, 42.191-192.

17. Chin Yi, Tsai Tsen. The minimal erythema dose of 311-nm Narrow-band UVB in Taiwanese. 2002; From department of dermatology, National Taiwan University Hospital. 